The Digital Object Identifier - DOI: 10.37952/ROI-jbc-01/20-64-12-18

Submitted on December 12, 2020.

\title{
Quality control of milk powder with near-infrared spectroscopy
}

\author{
(C) Yulia G. Ataeva, and Alsu R. Makaeva** \\ Test Center of the Federal State Budgetary Scientific Institution «Federal Center for Toxicological, \\ Radiation, and Biological Safety». Kazan, 420075. Tatarstan Republic. Russia. \\ Phone: +7 (843)239-53-29.E-mail:ic@vnivi.ru
}

*Supervising author; ${ }^{+}$Corresponding author

Keywords: milk powder, NIR-spectroscopy, protein, fat, moisture.

\begin{abstract}
Milk is one of the most widely consumed food products in the world and is often used in the manufacture of various food products. To reduce the cost of transportation and storage, as well as extend the shelf life of milk, it is dried. It retains most of the nutritional and organoleptic properties of liquid milk. Currently, at least $20-30 \%$ of the produced whole milk and fermented milk products are falsified. Flour, starch, chalk, lime, and even gypsum are mixed into milk powder. Classical methods of analysis of milk powder (gravimetric, titrimetric, acidic, etc.) do not allow assessing the qualitative composition of milk powder, while chromatographic and other methods require time and sample preparation. Therefore, to assess the quality of milk, methods of spectrometry in the near infrared region (NIR spectrometry) are becoming very popular. The objects of research were whole milk powder and skimmed milk powder, which were received for research at the Test Center of the FSBSI «Federal Center for Toxicology, Radiation and Biological Safety» from various manufacturers of the Russian Federation. We studied 22 samples of dried whole and skim milk using an IR spectrometer. According to the results of studies, it was found that, on average, samples of skimmed milk powder for all studied indicators corresponded to standards. In 54.5\% of the samples of dried whole milk, a reduced fat content was revealed and in $81.8 \%$, an increased content of lactose.
\end{abstract}

\section{References}

[1] GOST 33629-2015 Canned milk. Dry milk. Specifications. Official publication. Moscow: Standartinform. 2017. 9p. (russian)

[2] E.E. Illarionova, D.D. Bilal. On the issue of falsification of skimmed milk serum. Collection of scientific papers "Scientific support for the dairy industry". Moscow. 2004. P.141-145. (russian)

[3] T.V. Kobzeva. Assessment of the quality indices and identification of milk powder characteristics. Dairy industry. 2016. No.3. P.32-35. (russian)

[4] A.Kh. Tamayev, E.R. Kochisova. Safety and quality of milk powder sold in retail chain. Scientific works of students of the Gorsky State Agrarian University. 2019. Vol.56/1. P.228-230. (russian)

[5] A.N. Sharonov, S.A. Lopatin, S.M. Kuznetsov, S.A. Novoselov, V.F. Lopatina, V.V. Zakrevskiy, A.V. Zakrevskaya, E.V. Rakitskaya. Rationing and quality control as a conceptual basis for the development of military nutrition. Monograph. 2019. P.275-377. (russian)

[6] D. Cozzolino. Recent Trends on the Use of Infrared Spectroscopy to Trace and Authenticate Natural and Agricultural Food Products. Applied Spectroscopy Reviews. 2012. P.518-530.

[7] I. Matraszek-Zuchowska, B. Wozniak, A. Posyniak. Determination of Hormones Residues in Milk by Gas Chromatography-Mass Spectrometry. Food Anal. Methods. 2017. No.10. P.727-739.

[8] L.E. Rodriguez-Saona, M.E. Allendorf. Use of FTIR for Rapid Authentication and Detection of Adulteration of Food. Annu. Rev. Food Sci. Technol. 2011. No.2. P.467-483. 